\title{
Wormort $\mathfrak{z u r}_{\mathfrak{u}}$ adhten Auflage des $\mathfrak{z}^{\text {weiten }}$ Bandes.
}

Jn dem zweiten $B$ ande jind Titel 12 und 16 von dem Regierungârath $\mathfrak{B}$ ier =

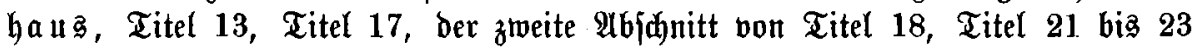

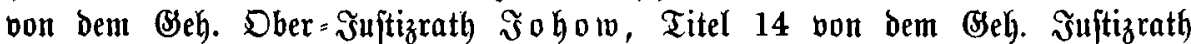
Frofejpr Dr. Sinjhiug und Titel 15, Titel 18 Ubjonnitt 1, Titel 19 und 20

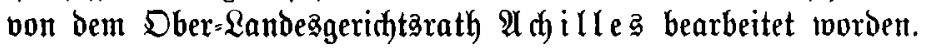


